2 Penketh A, Knight RK, Hodson ME, Batten JC. Management of pneumothorax in adults with cystic fibrosis. Thorax 1982 ; 37:850-3.

3 Spector ML, Stern RC. Pneumothorax in cystic fibrosis: a 26 year experience. Ann Thorac Surg 1989;47:204-7.

4 Hodson ME. Cystic fibrosis in adults. In: Brewis RAL, Gibson GJ, Geddes DM, eds. Respiratory medicine. London: Bailliere Tindall, 1990:783.

5 Hazelrigg SR, Landreneau RJ, Mack M, Acuff T, Seifert PE, Auer JE, et al. M. Thoracoscopic stapled resection for spontaneous pneumothorax. F Thorac Cardiovasc Surg 1993; 105:389-93.
6 Heimlich HJ. Heimlich flutter valve: effective replacement for drainage bottle. Hospital Topics 1965;43:122-3.

7 Mercier C, Page A, Verdant A, Cossette R, Dontigny L, Pelletier LC. Outpatient management of intercostal tube drainage of spontaneous pneumothorax. Ann Thorac Surg 1976;22:163-5

8 Minami H, Saka H, Senda K, Horio Y, Iwahara T, Nomura $\mathrm{F}$, et al. Small caliber catheter drainage for spontaneous pneumothorax. Am f Med Sci 1992;304:345-7.

9 Mainini SE, Johnson FE. Tension pneumothorax complicating small-caliber chest tube insertion. Chest 1990;97: $759-60$

Thorax 1994;49:1179-1180

\section{Empyema and mediastinitis complicating retropharyngeal abscess}

Masazumi Watanabe, Yoshiro Ohshika, Teruhiro Aoki, Keigo Takagi, Susumu Tanaka, Toshiro Ogata

\begin{abstract}
A 21 year old man with a retropharyngeal abscess complained of right sided chest pain, and chest radiography and thoracocentesis revealed an empyema. A computed tomographic scan of the chest showed a posterior mediastinal abscess communicating with the right pleural cavity. Emergency thoracotomy was performed and the mediastinal abscess and empyema were drained.
\end{abstract}

(Thorax 1994;49:1179-1180)

Acute empyema following a retropharyngeal abscess and mediastinitis in an adult is very rare and often fatal. ${ }^{12}$ This report presents a case that was cured with surgical intervention.

\section{Case report}

A 21 year old man was admitted with a high fever to our hospital complaining of dysphagia and a four day history of a sore throat for which he was given oral antibiotics. On admission physical examination disclosed diffuse erythema and swelling of the pharynx and swelling and tenderness of the right side of the neck, but cervical lymph adenopathy was not present. There were no abnormal dental findings and the tonsils appeared normal. A chest radiograph showed widening of the upper mediastinum, and radiography of the soft tissues of the neck showed retropharyngeal gas and widening of the retropharyngeal space. A transoral retropharyngeal tap was performed and pus was obtained consistent with a retropharyngeal abscess. Cultures grew $\alpha$-streptococcus, $\beta$-streptococcus and staphylococcus. His white cell count was $13100 / \mathrm{mm}^{3}$ and the serum level of Creactive protein (CRP), a non-specific marker for acute inflammation, was $37 \cdot 8 \mathrm{mg} / \mathrm{dl}$.
Treatment was started with intravenous cefmetazole to which these organisms proved sensitive. The following day he developed right sided chest pain and radiographs showed a right pleural effusion. Pus was obtained during thoracocentesis and a chest tube was inserted immediately. The pleural effusion grew the same microorganisms as the retropharyngeal pus and the patient's mediastinitis appeared consequent to the retropharyngeal abscess which had perforated into the pleural cavity. An oesophagogram was normal. The patient's condition rapidly improved, temperature became normal, and both the pharyngeal and cervical swelling improved, but a computed tomographic scan of the chest on the fifth hospital day showed an increasing encapsulated mediastinal abscess between the oesophagus and vertebral bodies (fig 1). Since the mediastinal abscess had not been drained adequately a right thoracotomy was performed on the seventh hospital day, and $200 \mathrm{ml}$ of turbid, yellow-white fluid obtained. The upper mediastinal pleura appeared swollen between the superior vena cava and vertebral

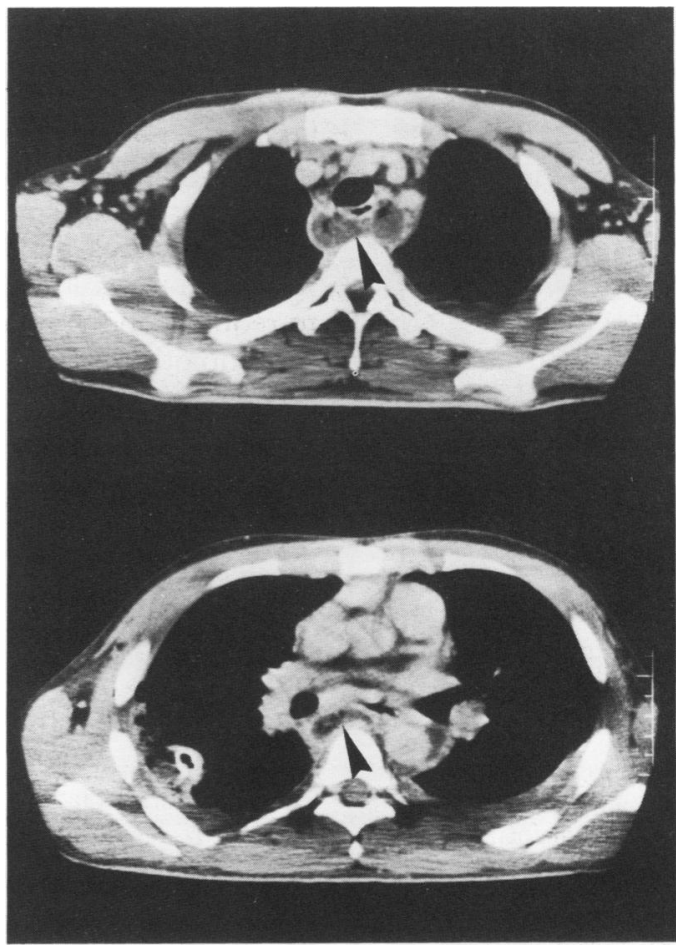

Figure 1 Computed tomographic scan of the chest. Arrow heads point to the encapsulated posterior mediastinal abscess between the oesophagus and the vertebral bodies. A chest tube was already inserted in the right pleural cavity. 


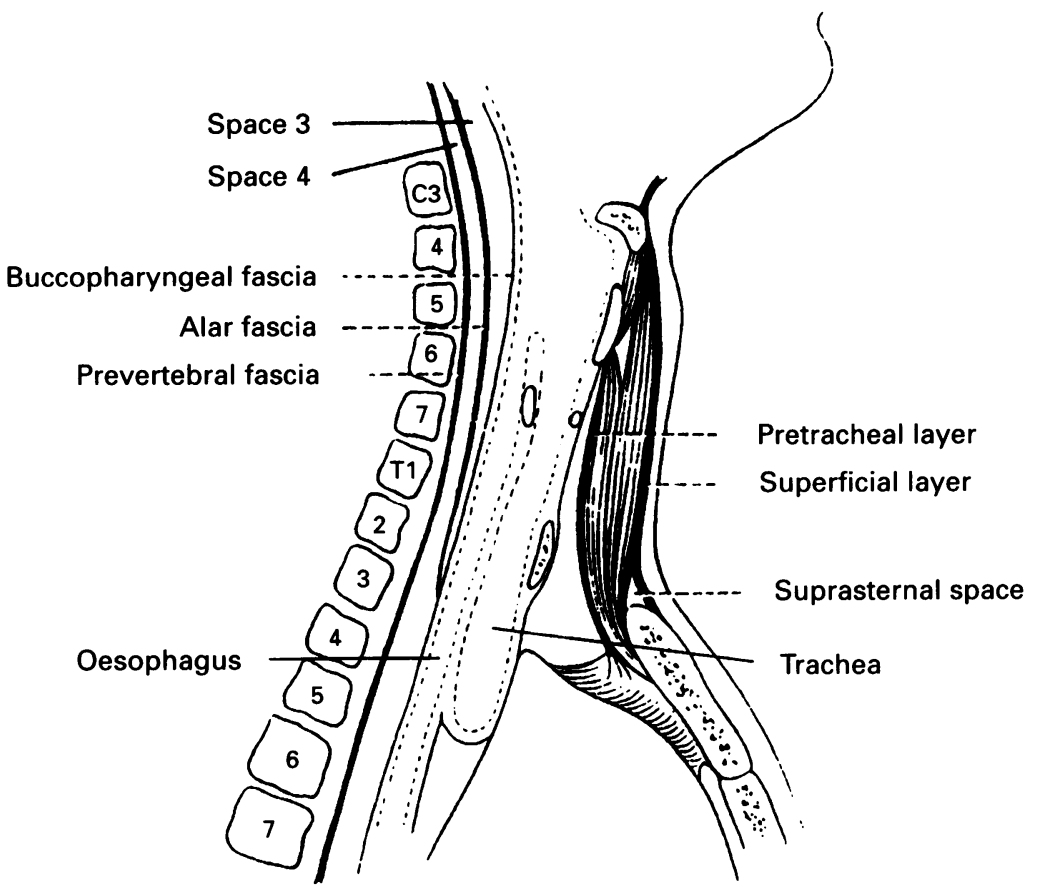

Figure 2 The fascial layers of the neck in longitudinal section. (After Hollinshead WF. Anatomy for surgeons. 1982:272.)

body. This abscess space had drained into the pleural space just below the carina. The entire posterior mediastinal pleura was opened for drainage and two chest tubes were inserted.

Three weeks after the operation the chest tubes were removed and the patient discharged. Postoperative evaluation failed to reveal any immunological deficiency. He remained well at follow up 11 months later.

\section{Discussion}

A major cause of suppurative mediastinitis is oesophageal perforation, either by foreign bodies or trauma. Odontic infections and retropharyngeal abscesses such as described here rarely cause mediastinitis..$^{3-5}$ Reports describing acute empyema following a retropharyngeal abscess and mediastinitis in an adult are very rare, ${ }^{1}$ and to our knowledge only one case has been reported to have survived. ${ }^{2}$

The retropharyngeal space consists of loose connective tissue between the buccopharyngeal fascia and prevertebral fascia. It is divided into two spaces by the alar fascia (fig 2). The anterior section is known as space 3 while the posterior part is known as space 4 . Space 3 extends down to the level of the second thoracic vertebra, but space 4 extends down to the diaphragm, behind the oesophagus in the posterior mediastinum. ${ }^{67}$ In our case the retropharyngeal abscess probably spread behind the alar fascia to cause a posterior mediastinal abscess which then drained into the right pleural cavity. In such cases treatment includes systemic antibiotic therapy and abscess drainage. If the abscess space is limited to the retropharyngeal space and posterior mediastinum, transcervical drainage should first be performed. ${ }^{8}$ We approached the abscess space via a right thoracotomy in order to drain both the posterior mediastinal abscess and the right sided empyema.

Treatment of this condition depends on an accurate and prompt diagnosis. The combination of surgery and effective antibiotic therapy is important in leading to a successful outcome.

1 Mukau L. Dissecting retropharyngeal abscess due to Fusobacterium necrophorum in an adult. South Med F 1985;78:4768.

2 Calandra GB, Mackowiak PA. Retropharyngeal abscess, mediastinitis, and pleural effusion complicating streptococcal facial erysipelas. South Med $\mathcal{f}$ 1981;74:1031-2.

3 Murray PM Finegold SM Anaerobic mediastinitis. Rev Infect Dis 1984;6:s123-7.

4 Ramilo J, Harris VJ, White H. Empyema as a complication of retropharyngeal and neck abscesses in children. Radiology 1978;126:743-6.

5 Zachariades N, Mezitis M, Starvrinidis P, Konsolaki-Agouridaki E. Mediastinitis, thoracic empyema, and pericarditis as complications of a dental abscess: report of a case. 7 Oral Maxillofac Surg 1988;46:493-5.

6 Grodinsky M, Holyoke EA. The fascia and fascial spaces of the head and neck and adjacent regions. Am $\mathcal{f} A n a t$ 1938;63:367-407.

7 Hollinshead WF. The fascia and spaces below the hyoid bone. Anatomy for surgeons. New York: Harper \& Row, 1982: Anatomy

8 Levine TM, Wurster CF, Krespi YP. Mediastinitis occurring as a complication of odontogenic infections. Laryngoscope 1986;96:747-50. 